\title{
The Glacier Inventory of China
}

\author{
SHI Yafeng, LIU Chaohai, KANG Ersi \\ Cold and Arid Regions Environmental and Engineering Research Institute, Chinese Academy of Sciences, \\ Lanzhou 730000, China \\ E-mail: eskang@Izb.ac.cn
}

\begin{abstract}
Following recommendations from the International Commission on Snow and Ice for a world glacier inventory, an inventory of glaciers in China was carried out by Chinese glaciologists from 1978 to 2002. Each glacier was measured from aerial photographs and topographical maps and 34 parameters recorded. These parameters were then analyzed statistically for the various river systems in China. Twelve volumes of the Glacier Inventory of China (GIC) have been published, consisting of 22 parts in 21 books. The data were subsequently abridged into a Concise GIC, published in Chinese (2005) and in English (2008), to make the glacier inventory more accessible and better adapted for assessing glacier response to climate change. After the GIC was completed, new aerial photographs became available and remote-sensing techniques became more common. To investigate glacier changes since completion of the first GIC, a second Glacier Inventory of China was initiated in 2007. This 5 year project, supported by the Ministry of Science and Technology, will be undertaken mainly using remotesensing techniques.
\end{abstract}

\section{INTRODUCTION}

In September 1978, the International Commission on Snow and Ice (ICSI) held a workshop on World Glacier Inventory in Switzerland, attended by scientists from 19 countries. F. Müller pointed out in his introduction to the workshop (Müller and Scherler, 1980) that completion of a world glacier inventory was important for three reasons. Firstly, it would enrich our knowledge of local, regional and global hydrological cycles and water budgets. Secondly, it would generate the basic data needed for managing freshwater resources and hydropower, and for irrigation, disaster prevention, recreation and tourism. Thirdly, it would provide necessary background information for studying climatic processes and monitoring climate change. His revised guide book (Müller and others, 1977) was accepted by participants at the workshop as the standard for the measurement and calculation of the 40 glacier parameters which are the basis for the World Glacier Inventory. By 1978, five countries the USSR, Norway, Austria, Switzerland and Sweden - had completed glacier inventories, but most glacierized countries had yet to carry out the task. As head of the Chinese delegation, and on behalf of the Lanzhou Institute of Glaciology and Geocryology (LIGG), now the Cold and Arid Regions Environmental and Engineering Research Institute of the Chinese Academy of Sciences (CAS), Shi Yafeng declared that LIGG would carry out a Glacier Inventory of China (GIC) using these guidelines (Shi and others, 2008a, p. 7, 23-24).

\section{EARLY STAGE OF THE GLACIER INVENTORY OF CHINA}

Smooth progress during the initial stages of the GIC led to the completion of inventories of glaciers in the Qilian Shan, Altai Shan and Tien Shan in northwest China.

In 1979, a GIC working group of some 15 glaciologists and technicians, headed by Wang Zongtai and Liu Chaohai, was set up by LIGG. They studied the guidelines and chose the Qilian Shan for a pilot study. A complete set of aerial photographs and large-scale topographic maps of the mountains were collected. Glacier distributions were carefully checked with the maps, aerial photographs and field investigations, and 34 glacier parameters measured and calculated from the maps. In 1981, the first volume of the GIC, on the Qilian Shan, was published (Wang and others, 1981). It contained various statistical tables summarizing the glacier parameters in different hydrological basins, $1: 250000$ scale maps of the glacier distribution, and two introductory papers. The results of this inventory showed that in the Qilian Shan there were 2815 glaciers covering $1931 \mathrm{~km}^{2}$ with an estimated ice volume of $93 \mathrm{~km}^{3}$.

In 1980, the working group sent a small field team, headed by Liu Chaohai, to investigate the glaciers in the Altai Shan, the northernmost glacierized area in China. The second volume of the GIC followed shortly afterwards in 1982 (Liu and others, 1982). In the Altai Shan there are 403 glaciers covering an area of $280 \mathrm{~km}^{2}$ with an estimated ice volume of $16 \mathrm{~km}^{3}$.

The Chinese Tien Shan have the largest number of glaciers of any mountain range in northwest China. The working group, now enlarged with more scientists and technicians, started to compile the inventory for this region in 1980. At the same time, Zhu Guocai succeeded in producing a radio-echo sounding radar that could accurately measure glacier thickness, significantly improving the ability to calculate ice volumes (Shi and others, 2008b, p.14-21). In 1986 and 1987, the four parts in four books of the Tien Shan glacier inventory volume, the main contributors to which were Liu Chaohai, Wang Yinsheng, Lai Zuming, Xie Weirong and Ding Lianfu, were published (Ding and others, 1986; Lai and others, 1986; Wang and others, 1986; Xie and others, 1987). In the Tien Shan, 9035 glaciers cover $9225 \mathrm{~km}^{2}$ with an estimated ice storage of $1011 \mathrm{~km}^{3}$.

\section{LATER STAGE OF THE GLACIER INVENTORY OF CHINA}

In the late 1980s and early 1990s, the GIC encountered difficulties from reduced resources and personnel so that progress slowed. However, it was possible to publish the 


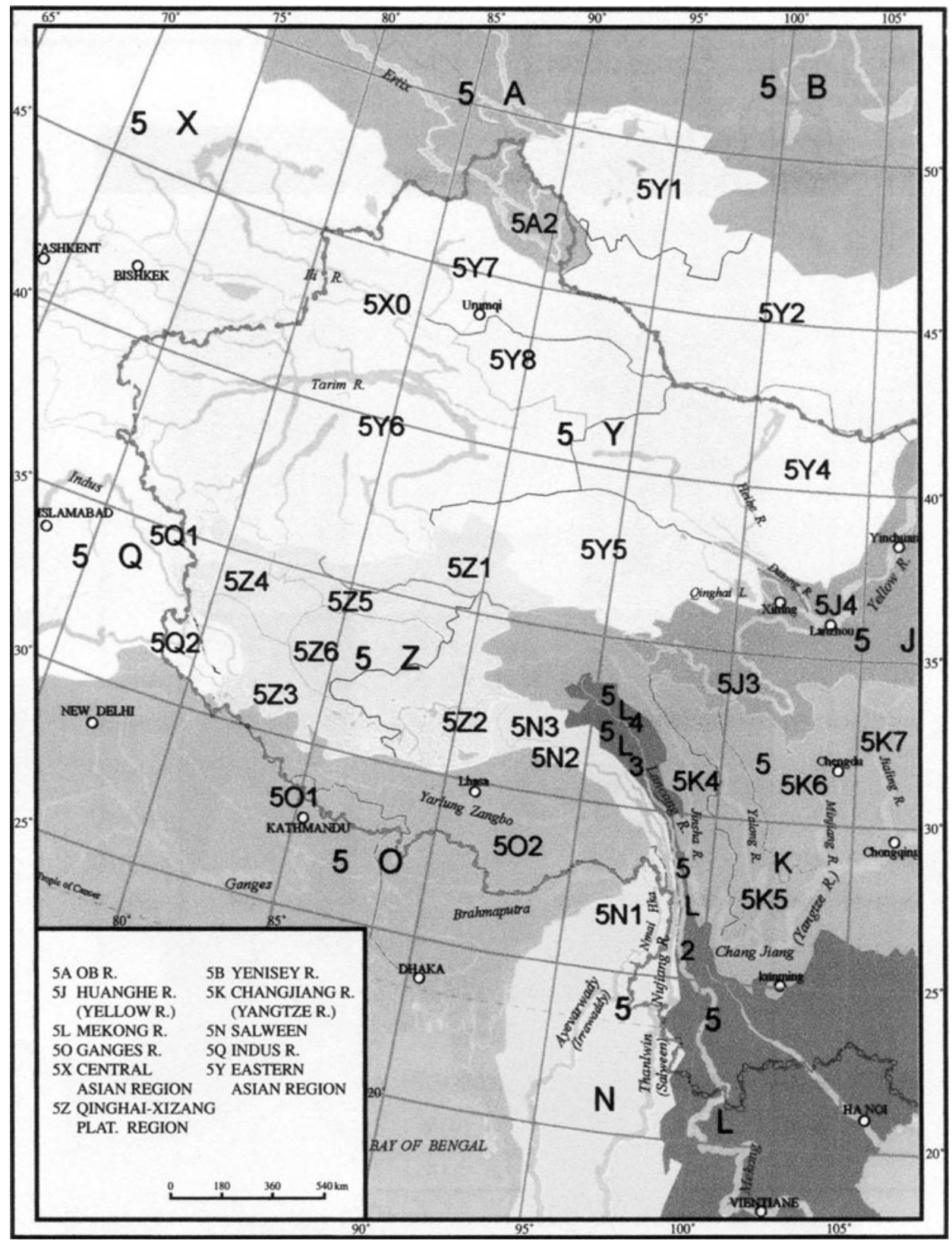

Fig. 1. Hydrological basins in China and adjacent areas related to the GIC (from Shi and others, 2008a).

volume of five parts in five books covering the interior area of the Qinghai-Tibetan Plateau in 1988 (Jiao and Zhang, 1988a,b,c; Yang and An, 1988; Zhang and Jiao, 1988), the main contributors to which were Jiao Keqin, Zhang Zhenshuan and Yang Hui'an. In this vast, desolate and cold plateau area, there were 5341 glaciers covering $7836 \mathrm{~km}^{2}$ with an estimated ice volume of $777.5 \mathrm{~km}^{3}$. Glaciers are highly concentrated along the southern flank of the western Kunlun Shan, where the broad planation surface is at about $6000 \mathrm{~m}$ a.s.l. and glaciers cover an area of $3000 \mathrm{~km}^{2}$. Puruogangri is the largest icefield. It is located in the mideastern part of this interior area and has an area of $422.85 \mathrm{~km}^{2}$. One other book, on the Chinese Pamirs, was also published in 1988 (Luo and others, 1988). Between 1989 and 1994, two volumes of the GIC were published: one in a book on the Yarkant river basin in the Karakoram (Yang and An, 1989); and another in four parts in four books on drainage basins in the Kunlun Shan, covering the southern Qaidam basin, and the Yellow River, Hotan river,
Karamiran-Keriya rivers and Miran-Qarqan rivers (Yang and An, 1992a,b, 1994a,b). The principal contributors to these publications were Yang Hui'an and An Ruizhen. In 2001, a revised edition of the original Chinese Pamirs inventory, covering the Kaxgar river basin, was published (Liu and others, 2001), to complete the volume consisting of a part in two books. At that point, we recognized that the Tarim interior basin has the most glaciers, and is the largest glaciercovered area, in China. The number of glaciers here was 11655 , covering an area of $19878 \mathrm{~km}^{2}$, with an estimated ice volume of $2312 \mathrm{~km}^{3}$. For the international rivers, it is found that there are 2248 glaciers covering an area of $4297 \mathrm{~km}^{2}$, with an ice storage of $3993 \mathrm{~km}^{3}$ outside of Chinese territory. The vast Taklamakan sandy desert is located in the central lowland area of the Tarim basin which is extremely dry. However, relatively abundant precipitation and numerous glaciers in the surrounding mountains supply rich ice and snow meltwater and mountain runoff, nourishing natural and artificial oases in the 
Table 1. Glaciers in the internal and external drainage basins of China (from Shi and others, 2008a)

\begin{tabular}{lcccccc}
\hline $\begin{array}{l}\text { Drainage } \\
\text { basins }\end{array}$ & Number of glaciers & \multicolumn{2}{c}{ Glacier area } & \multicolumn{2}{c}{ Ice volume } \\
& & & & & & \\
& & & $\mathrm{km}^{2}$ & $\%$ & $\mathrm{~km}^{3}$ & $\%$ \\
\hline Internal & 27024 & 58.27 & 35469 & 59.69 & 3575 & 63.84 \\
$\begin{array}{l}\text { External } \\
\text { Total }\end{array}$ & 19353 & 41.73 & 23956 & 40.31 & 2025 & 36.16 \\
& 46377 & 100 & 59425 & 100 & 5600 & 100 \\
\hline
\end{tabular}

pediment belt and the lowland areas. Glacier meltwater contributes about $38.5 \%$ of the total river runoff from the surrounding mountains of the Tarim basin (Shi and others, 2008b, p. 261-268).

The final group of five GIC volumes in three books was published from 1994 to 2002. They covered the following drainage basins: Changjiang (Yangtze) river ( $\mathrm{Pu}, 1994)$; Lancang (Mekong) and Lujiang rivers (Pu, 2001); and the Ganges (mainly the Yarlung Zangbo) and upper reaches of the Indus river (Mi and others, 2002). The main contributors to these publications were Pu Jianchen, Mi Desheng and Xie Zichu. All the rivers originating in the southeastern Tibetan Plateau belong to the exterior drainage systems, and most of the glaciers are classified as maritime temperate. There are 19355 glaciers covering an area of $23956 \mathrm{~km}^{2}$ with an estimated ice storage of $2025 \mathrm{~km}^{3}$ (including a small part of the $\mathrm{Ob}$ and Yellow rivers). The areas where the maritimetype glaciers develop receive much precipitation and possess plentiful water power. However, the areas suffer from frequent avalanches, serious debris flows and various flood disasters. In the meantime, a large-scale unified glacier inventory database for the GIC was developed by Wu Lizong using Geographical Information System techniques (Wu and $\mathrm{Li}, 2004)$.

\section{CONCISE GLACIER INVENTORY OF CHINA}

The 22 parts in 21 books of the 12 volumes comprising the completed GIC (Wu and others, 2004, p.116-135), with information on glacier distributions in the various hydrological basins of China, are convenient for practical applications, but too numerous to provide a clear and concise overview and scientific assessment of the glaciers in China. We therefore compiled an integrated and simplified review in one book, summarizing the main scientific aspects and data from the statistical analyses. The resultant Concise Glacier Inventory of China was published in Chinese in 2005, and in English in 2008 (Shi and others, 2008a). This book contains some corrections and revisions to the original data and includes some new research results on glacier change and runoff. The hydrological basins identified for the GIC are shown in Figure 1, and data on glacier distribution in the internal and external drainage basins of China are summarized in Table 1. The editor-in-chief of this book was Shi Yafeng, assisted by associate editors Liu Chaohai, Wang Zongtai, Liu Shiyin and Ye Baisheng and 13 other authors. It has been very well received and is considered as a general glaciology of China. In 2006, the success of the Glacier Inventory of China and its associated publications was recognized with the award of the Prize of National Science and Technology Progress (Second Class).

\section{CONCLUSION AND DISCUSSION}

The main deficiency of the GIC described above is the rather long time lag between the aerial photos and printing of the topographical maps. Users of the glacier-inventory data need to consider the time at which the inventory was completed in a specific region.

The measurement of ice thickness and estimation of ice volume were carried out using the ground-based radio-echo sounding techniques developed by the former LIGG and applied to representative glaciers. Airborne radar sounding of ice thickness has yet to be further developed and applied.

It took about 23 years to complete the first GIC, because the manual measurement of the numerous glaciers on the topographical maps and aerial photos is inefficient and timeconsuming, and at times the work was delayed by inadequate resources and other priorities.

Glaciers are changing rapidly, so a second GIC, that will use remote-sensing techniques, was started in 2007. This project will take 5 years to complete and will be invaluable for research into glacier change and for assessing water resources.

\section{REFERENCES}

Ding, L., W. Xie, C. Liu, C. Wang and Z. Wang, eds. 1986. Glacier inventory of China III. Tien Shan mountains (Ili River drainage basin). Beijing, Science Press. Academia Sinica, Lanzhou Institute of Glaciology and Geocryology. [In Chinese.]

Jiao, K. and Z. Zhang, eds. 1988a. Glacier inventory of China VII. Qinghai-Xizang Plateau interior area (drainage basins of Siling Lake). Beijing, Science Press. Academia Sinica, Lanzhou Institute of Glaciology and Geocryology. [In Chinese.]

Jiao, K. and Z. Zhang, eds. 1988b. Glacier inventory of China VII. Qinghai-Xizang Plateau interior area (drainage basins of the Dogaicoring and Yibuchaka Lakes). Beijing, Science Press. Academia Sinica, Lanzhou Institute of Glaciology and Geocryology. [In Chinese.]

Jiao, K. and Z. Zhang, eds. 1988c. Glacier inventory of China VII. Qinghai-Xizang Plateau interior area (drainage basins of Zharinam Lake). Beijing, Science Press. Academia Sinica, Lanzhou Institute of Glaciology and Geocryology. [In Chinese.]

Lai, Z. and 7 others, eds. 1986. Glacier inventory of China III. Tien Shan mountains (interior drainage area of Junggar Basin in northwest). Beijing, Science Press. Academia Sinica, Lanzhou Institute of Glaciology and Geocryology. [In Chinese.]

Liu, C., G. You and J. Pu, eds. 1982. Glacier inventory of China II. Altai mountains. Beijing, Science Press. Academia Sinica, Lanzhou Institute of Glaciology and Cryopedology. [In Chinese with English summary.]

Liu, C., Z. Wang, L. Ding, D. Mi and H. Yang, eds. 2001. Glacier inventory of China IV. Pamirs (drainage basins of Kaxgar River and others). Revised edition. Lanzhou, Gansu Culture Publishing House. Academia Sinica, Lanzhou Institute of Glaciology and Geocryology. [In Chinese.]

Luo, X., D. Mi and C. Liu, eds. 1988. Glacier inventory of China IV. Pamirs. Beijing, Science Press. Academia Sinica, Lanzhou Institute of Glaciology and Geocryology. [In Chinese.]

Mi, D., Z. Xie, X. Luo, Q. Feng, M. Ma and D. Jin, eds. 2002. Glacier inventory of China XI. The Ganga drainage basin. XII. The Indus drainage basin. Xi'an, Xi'an Cartographic Publishing House. Academia Sinica, Lanzhou Institute of Glaciology and Geocryology. [In Chinese.]

Müller, F. and K. Scherler. 1980. Introduction to the world glacier inventory. IAHS Publ. 126 (Riederalp Workshop 1978 - World Glacier Inventory), xiii-xx.

Müller, F., T. Caflisch and G. Müller 1977. Instructions for the compilation and assemblage of data for a world glacier 
inventory. Zürich, IAHS(ICSI)/UNEP/UNESCO. Temporary Technical Secretariat for the World Glacier Inventory. Swiss Federal Institute of Technology (ETH).

Pu, J., ed. 1994. Glacier inventory of China VIII. The Changjiang (Yangtze) River drainage basin. Lanzhou, Gansu Culture Publishing House. Academia Sinica, Lanzhou Institute of Glaciology and Geocryology. [In Chinese.]

$\mathrm{Pu}$, J., ed. 2001. Glacier inventory of China IX. The Lancang river. $X$. The Nujiang river. Xi'an, Xi'an Cartographic Publishing House. [In Chinese.]

Shi, Y., S. Liu, B. Ye, C. Liu and Z. Wang, eds. 2008a. Concise glacier inventory of China. Shanghai, Shanghai Popular Science Press.

Shi, Y., M. Huang, T. Yao and Y. He, eds. 2008b. Glaciers and related environments in China. Beijing, Science Press.

Wang, Y. and 7 others, eds. 1986. Glacier inventory of China III. Tien Shan mountains (interior drainage area of scattered flow in east). Beijing, Science Press. Academia Sinica, Lanzhou Institute of Glaciology and Geocryology. [In Chinese.]

Wang, Z., C. Liu, G. You, J. Pu, H. Yang and P. Tian, eds. 1981. Glacier inventory of China I. Qilian mountains. Beijing, Science Press. Academia Sinica, Lanzhou Institute of Glaciology and Cryopedology. [In Chinese.]

Wu, L. and X. Li, eds. 2004. China glacier information system. Beijing, Ocean Press. [In Chinese.]

Xie, W., L. Ding, C. Liu, K. Jiao, C. Wang and Z. Wang eds. 1987. Glacier inventory of China III. Tien Shan Mountains (interior drainage area of Tarim Basin in southwest). Beijing, Science Press. Academia Sinica, Lanzhou Institute of Glaciology and Geocryology. [In Chinese.]
Yang, H. and R. An, eds. 1988. Glacier inventory of China VII. Qinghai-Xizang Plateau interior area (drainage basins of Ayakkum lake and Hoh Xil lake). Beijing, Science Press. Academia Sinica, Lanzhou Institute of Glaciology and Geocryology. [In Chinese.]

Yang, H. and R. An, eds. 1989. Glacier inventory of China V. Karakorum Mountains (drainage basin of the Yarkant River). Beijing, Science Press. Academia Sinica, Lanzhou Institute of Glaciology and Geocryology. [In Chinese.]

Yang, H. and R. An eds. 1992a. Glacier inventory of China VI. Kunlun Mountains (drainage area of southern Qaidam basin and upper reaches of Yellow River). Lanzhou, Science Press. Academia Sinica, Lanzhou Institute of Glaciology and Geocryology. [In Chinese.]

Yang, H. and R. An, eds. 1992b. Glacier inventory of China VI. Kunlun Mountains (interior drainage area of Hotan River). Lanzhou, Science Press. Academia Sinica, Lanzhou Institute of Glaciology and Geocryology. [In Chinese.]

Yang, H. and R. An, eds. 1994a. Glacier inventory of China VI. Kunlun Mountains (interior drainage area of Karamiran-Keriya river). Lanzhou, Science Press. Academia Sinica, Lanzhou Institute of Glaciology and Geocryology. [In Chinese.]

Yang, H. and R. An, eds. 1994b. Glacier inventory of China VI. Kunlun Mountains (interior drainage area of Miran-Qarqan river). Lanzhou, Science Press. Academia Sinica, Lanzhou Institute of Glaciology and Geocryology. [In Chinese.]

Zhang, Z. and K. Jiao, eds. 1988. Glacier inventory of China VII. Qinghai-Xizang Plateau interior area (drainage basins of Banggong lake). Beijing, Science Press. Academia Sinica, Lanzhou Institute of Glaciology and Geocryology. [In Chinese.] 